\title{
Graphene composites containing chemically bonded metal oxides
}

\author{
K PRAMODA $^{\mathrm{a}}$, S SURESH ${ }^{\mathrm{a}}$, H S S RAMAKRISHNA MATTE ${ }^{\mathrm{a}}$ and A GOVINDARAJ ${ }^{\mathrm{a}, \mathrm{b}, *}$ \\ ${ }^{a}$ New Chemistry Unit, Chemistry and Physics of Materials Unit, International Centre for Materials Science, \\ CSIR Centre of Excellence in Chemistry and Sheik Saqr Laboratory, Jawaharlal Nehru Centre for Advanced \\ Scientific Research, Jakkur P.O., Bangalore 560 064, India \\ ${ }^{\mathrm{b}}$ Solid State and Structural Chemistry Unit, Indian Institute of Science, Bangalore 560 012, India
}

MS received 8 May 2013

\begin{abstract}
Composites of graphene involving chemically bonded nano films of metal oxides have been prepared by reacting graphene containing surface oxygen functionalities with metal halide vapours followed by exposure to water vapour. The composites have been characterized by electron microscopy, atomic force microscopy and other techniques. Magnetite particles chemically bonded to graphene dispersible in various solvents have been prepared and they exhibit fairly high magnetization.
\end{abstract}

Keywords. Composites; oxides; thin films; electron microscopy; magnetic properties.

\section{Introduction}

After the discovery of graphene (Novoselov et al 2004; Geim and Novoselov 2007; Rao et al 2009; Rao and Sood 2013), there has been considerable research in the area of twodimensional materials, many of which are based on inorganic layered compounds (Novoselov et al 2005; Matte et al 2010; Coleman et al 2011). Several workers have prepared composites of these materials and studied their properties (Wang et al 2008; Cao et al 2012). An aspect of particular interest pertains to coating thin layers of metal oxides on the graphene surfaces to prepare useful composites. Such composites may indeed possess valuable properties, specially if the oxide layers are chemically bonded to graphene (Zhang et al 2010). The composites can be heated to high temperatures to generate thin oxide films. With this purpose, we have carried out the reactions of metal halide vapours with the oxygenated surfaces of graphene, followed by treatment with water vapour to prepare composites containing thin oxide films chemically bonded to graphene. By burning off the graphene, we obtain free-standing oxide nano-films. Thin films of metal oxides possess superior material properties (Miyauchi et al 2002; Kamegawa et al 2011). We have also prepared nanoparticles of magnetite chemically bonded to graphene to yield composites which are dispersible in many solvents.

\section{Experimental}

Graphite oxide (GO) was synthesized by the modified Hummer's method (Hummers and Offeman 1958). Graphene

\footnotetext{
*Author for correspondence (govind@jncasr.ac.in)
}

samples were obtained from graphite oxide by thermal exfoliation in a furnace preheated to $250{ }^{\circ} \mathrm{C}$. Figure 1 shows schematic diagram of experimental set up used for coating metal oxides onto graphene (Gomathi et al 2005). It consists of three glass chambers, one to contain the metal halide $\left(\mathrm{TiCl}_{4}, \mathrm{SiCl}_{4}\right.$, etc), the second for graphene and the third for water. High-vacuum stopcocks interconnect the chambers, which are connected to a vacuum pump. In a typical preparation, the sample chamber is evacuated for $15 \mathrm{~min}$ and the metal halide vapour from first chamber was allowed to enter

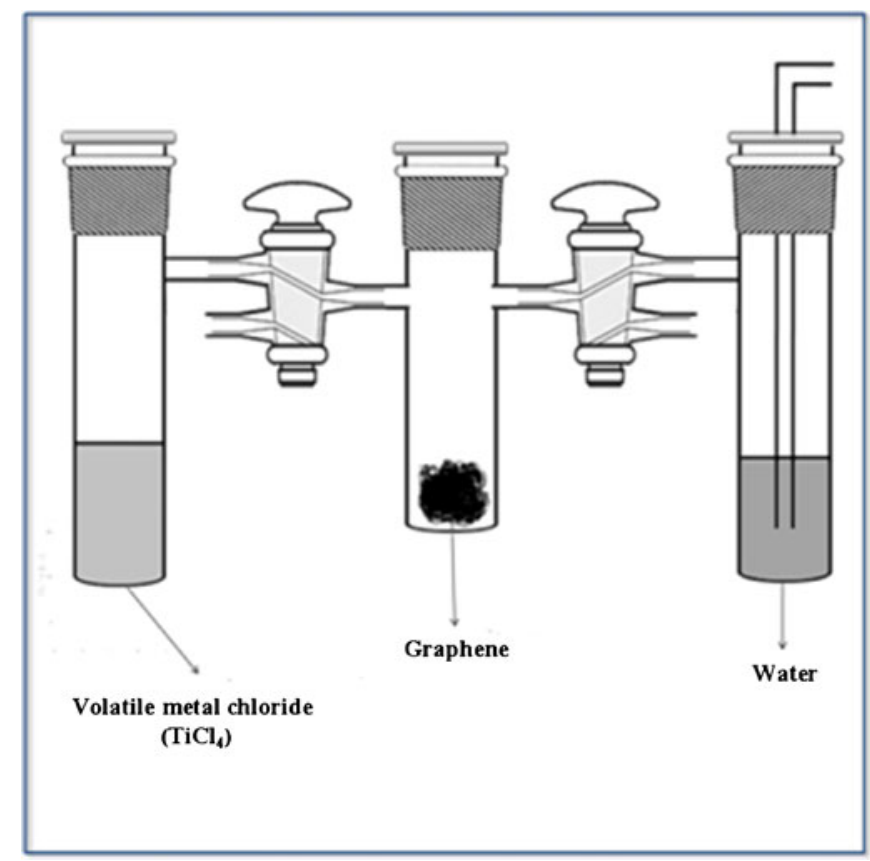

Figure 1. Schematic diagram of experimental set up. 

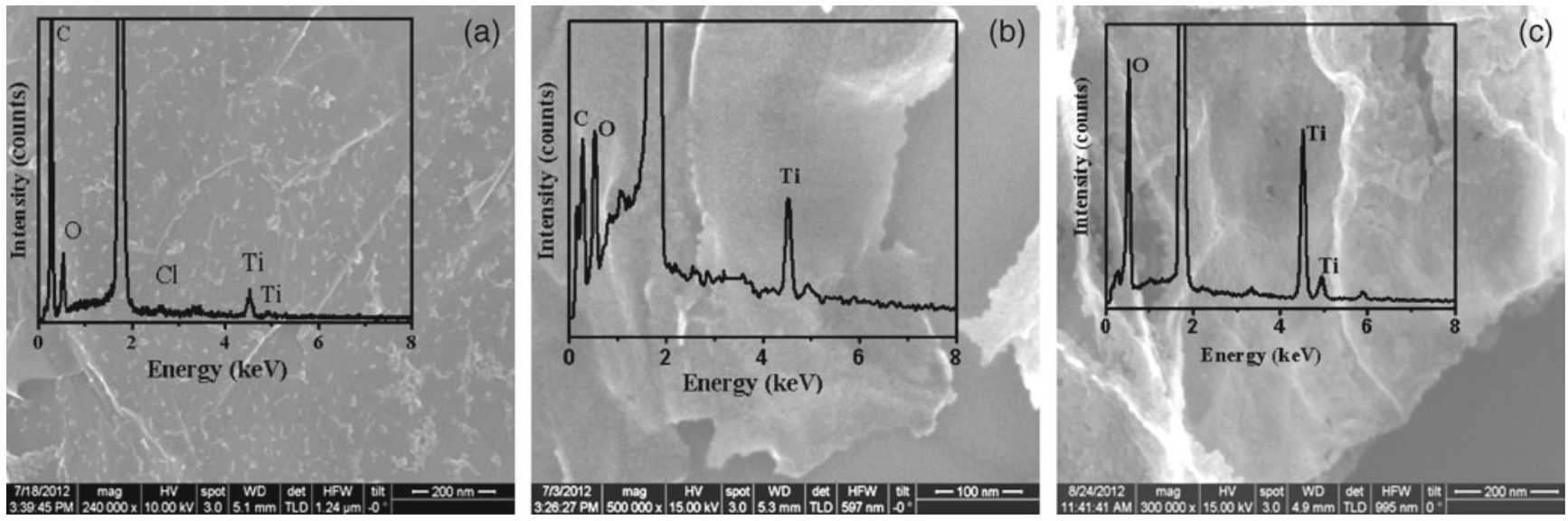

Figure 2. SEM images of (a) $\mathrm{TiO}_{2}$-bonded graphene prepared at room temperature, (b) same sample after calcination at $350{ }^{\circ} \mathrm{C}$ and (c) $\mathrm{TiO}_{2}$ nanosheets after removal of graphene at $600{ }^{\circ} \mathrm{C}$. Insets show EDX patterns.
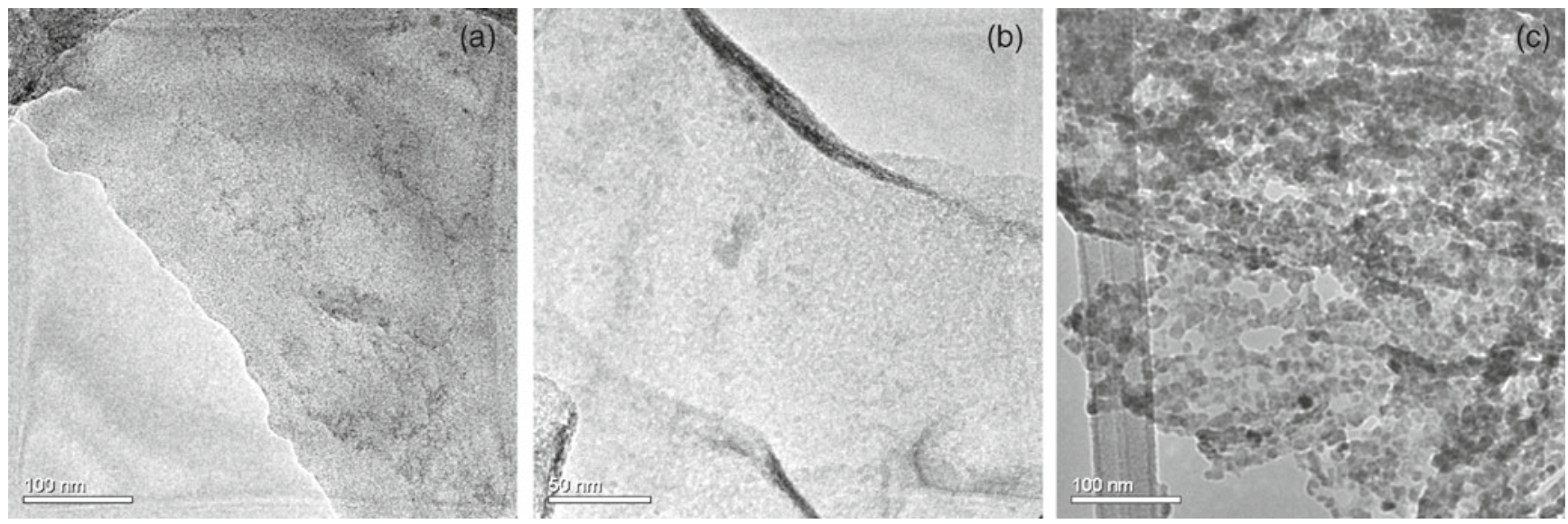

Figure 3. TEM images of (a) $\mathrm{TiO}_{2}$-bonded graphene prepared at room temperature, (b) same sample after calcination at $350{ }^{\circ} \mathrm{C}$ and (c) $\mathrm{TiO}_{2}$ nanosheets after removal of graphene at $600{ }^{\circ} \mathrm{C}$.

the reaction chamber and allowed to react for $10 \mathrm{~min}$, the unreacted metal halide vapour being removed by evacuation. In this step, the metal halide reacts with the oxygen functionalities on graphene giving out $\mathrm{HCl}$. Water vapour from the third chamber was then passed onto the sample chamber for hydrolyzing the remaining unreacted chlorines of the metal halide. These two procedures were repeated several times. The graphene samples so obtained were heated to $350{ }^{\circ} \mathrm{C}$ to produce metal oxide coatings. In the case of $\mathrm{TiO}_{2}$, the samples obtained after calcination at $350{ }^{\circ} \mathrm{C}$ and $600{ }^{\circ} \mathrm{C}$ for $12 \mathrm{~h}$ are designated as $\mathrm{G}-\mathrm{TiO}_{2}-350$ and $\mathrm{G}-\mathrm{TiO}_{2}-600$, respectively. The sample heated to $600{ }^{\circ} \mathrm{C}$ burned off the carbon giving only a thin free-standing film of $\mathrm{TiO}_{2}$.

To prepare graphene chemically bonded to $\mathrm{Fe}_{3} \mathrm{O}_{4}$, nanoparticles of $\mathrm{Fe}_{3} \mathrm{O}_{4}$ were prepared by the method reported in the literature (Zhang et al 2011). In a typical synthesis, $6.5 \mathrm{~g}$ of 1,6-hexadiamine, $2.0 \mathrm{~g}$ of sodium acetate and $1.0 \mathrm{~g}$ of $\mathrm{FeCl}_{3}$ were vigorously stirred in $30 \mathrm{ml}$ of ethylene glycol at $50{ }^{\circ} \mathrm{C}$ until a clear yellow solution was obtained. The resultant solution was transferred into a teflon-lined stainless-steel autoclave and kept at a temperature of $200{ }^{\circ} \mathrm{C}$ for $6 \mathrm{~h}$. The amine-coated $\mathrm{Fe}_{3} \mathrm{O}_{4}$ nanoparticles so obtained were reacted with graphene containing acid chloride groups (G-COCl). G-COCl was prepared by refluxing graphene oxide with excess of thionyl chloride for $12 \mathrm{~h}$, the excess thionyl chloride being removed under vacuum. In a typical reaction, $20 \mathrm{mg}$ of the amine-coated $\mathrm{Fe}_{3} \mathrm{O}_{4}$ was dispersed in $10 \mathrm{ml}$ dry DMF and sonicated for $10 \mathrm{~min}$. The suspension was added to $\mathrm{G}-\mathrm{COCl}$, sonicated for $10 \mathrm{~min}$ and refluxed at $70{ }^{\circ} \mathrm{C}$ for $12 \mathrm{~h}$ under nitrogen. The resultant solution was centrifuged and the solid product washed with water and ethanol and dried in vacuum.

X-ray diffraction (XRD) patterns were recorded with $\mathrm{CuK} \alpha$ radiation using a Rich-Siefert XRD-300-TT diffractometer. FTIR spectra were recorded with $\mathrm{KBr}$ pellet using Bruker Tensor 27. Scanning electron microscopic (SEM) images were recorded with a FEI NOVA NANOSEM 600. Transmission electron microscopic (TEM) images were viewed with a JEOL TEM 3010 instrument fitted with a Gatan CCD camera operating at an accelerating voltage of 

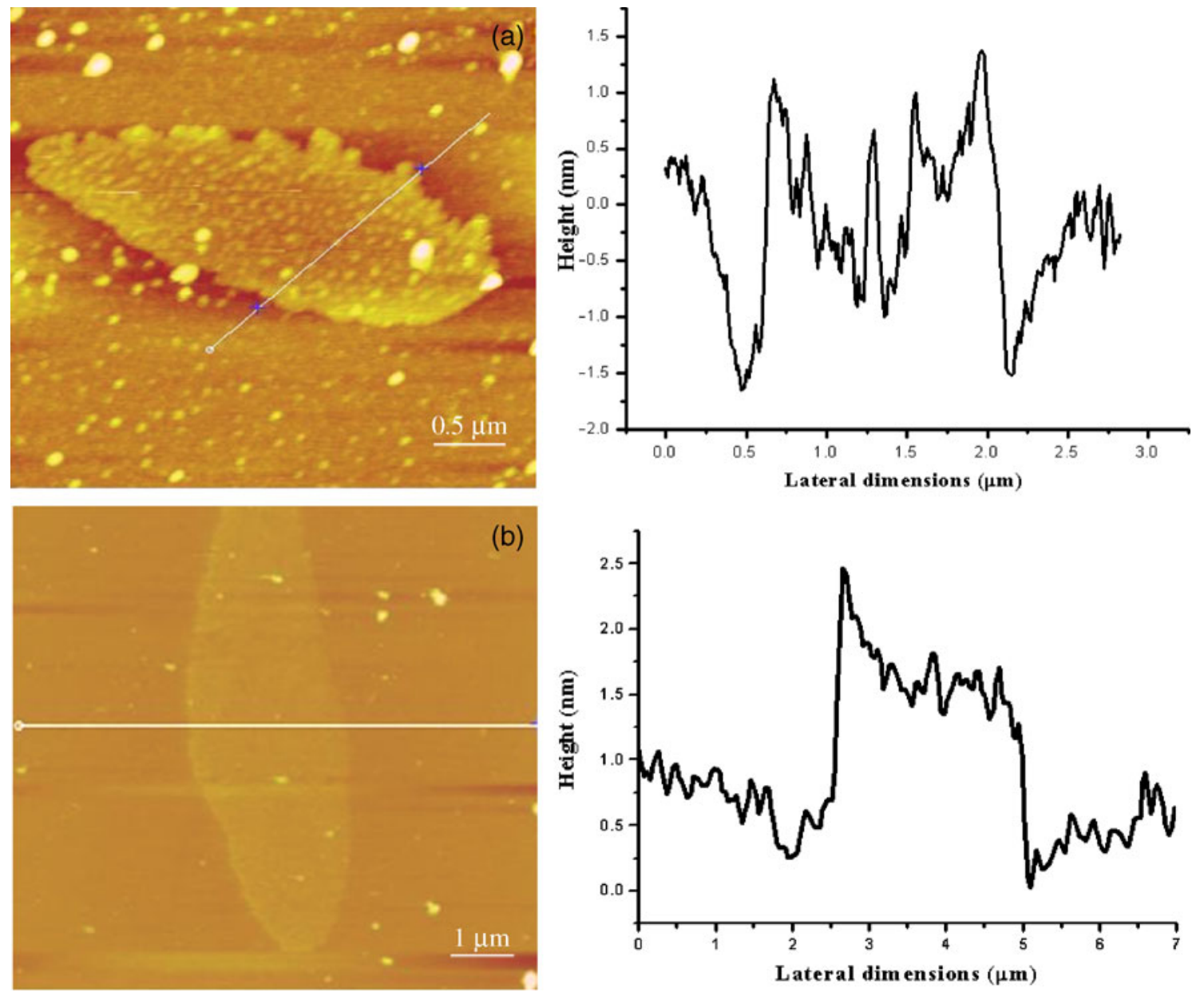

Figure 4. AFM images of (a) graphene- $\mathrm{TiO}_{2}$ composite after calcination at $350{ }^{\circ} \mathrm{C}$ and (b) $\mathrm{TiO}_{2}$ nanosheets after removal of graphene at $600{ }^{\circ} \mathrm{C}$. Height profiles are given.

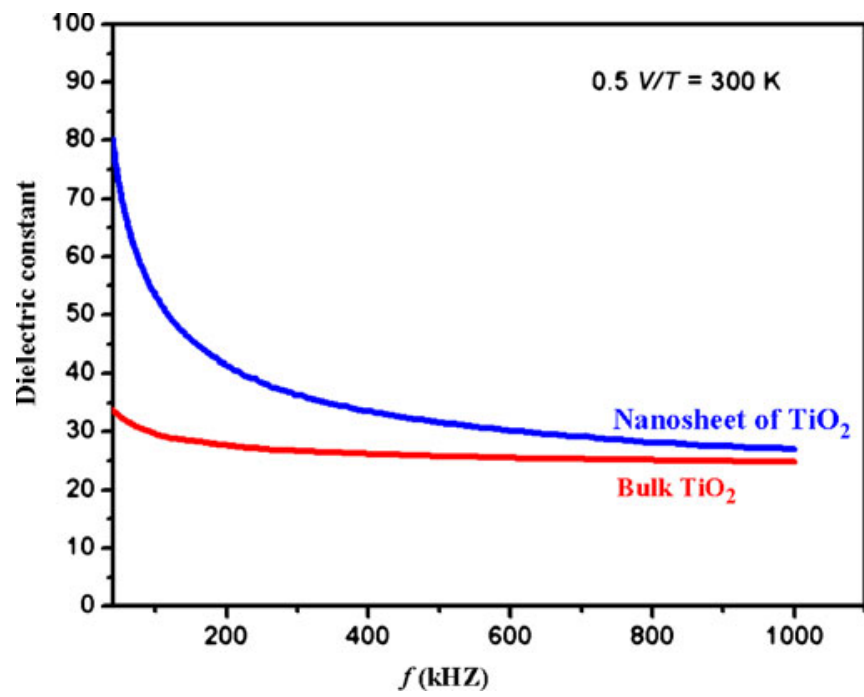

Figure 5. Frequency-dependent dielectric constant of $\mathrm{TiO}_{2}$ nanosheets compared to bulk $\mathrm{TiO}_{2}$.
$300 \mathrm{kV}$. Atomic force microscope (AFM) measurements were performed using an Innova atomic microscope. $M-H$ measurements were performed via superconducting quantum interface device (SQUID) magnetometer at $300 \mathrm{~K}$.

\section{Results and discussion}

The method employed by us to prepare graphene chemically bonded to metal oxide films, by employing the experimental set up shown in figure 1 , gives rise to $\mathrm{M}-\mathrm{O}-\mathrm{C}$ bonds. Reaction with water vapour results in hydrolysis of the unreacted chlorine, which on calcination gives oxidic species. Thus, in the case of $\mathrm{TiCl}_{4}$, we obtain a coating of $\mathrm{TiO}_{2}$ film on graphene by this means. The thickness of the oxide layers depends on the number of times we carry out the reaction with the metal halide. In figure 2, we show SEM images of $\mathrm{TiO}_{2}$ chemically bonded to graphene $\left(\mathrm{G}-\mathrm{TiO}_{2}\right)$ obtained after the reaction of $\mathrm{TiCl}_{4}$ with graphene at room temperature and subjected to calcination at different temperatures. The energy-dispersive X-ray analysis (EDX) pattern given in the inset of figure 2(a) shows presence of $\mathrm{Ti}, \mathrm{O}$ and $\mathrm{Cl}$ in the sample prepared at room temperature. Chlorine is absent 

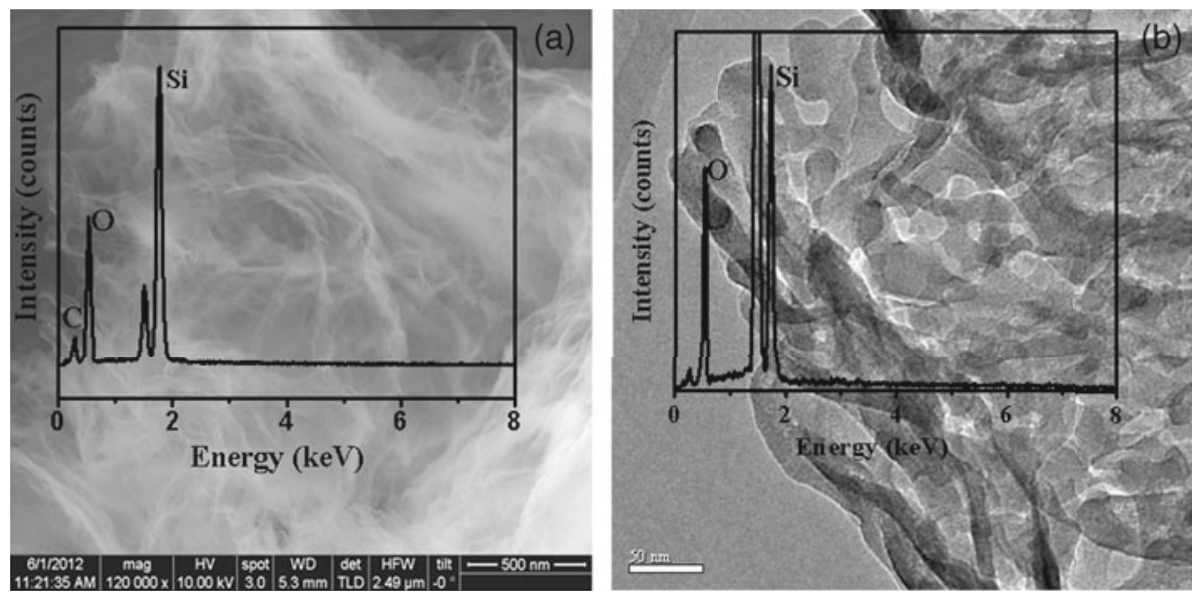

Figure 6. (a) $\mathrm{SEM}$ image of $\mathrm{SiO}_{2}$-bonded graphene calcined at $350{ }^{\circ} \mathrm{C}$ and (b) TEM image of $\mathrm{SiO}_{2}$ nanosheets obtained after calcination of $\mathrm{SiO}_{2}$-bonded graphene at $600{ }^{\circ} \mathrm{C}$. Insets show EDX patterns.
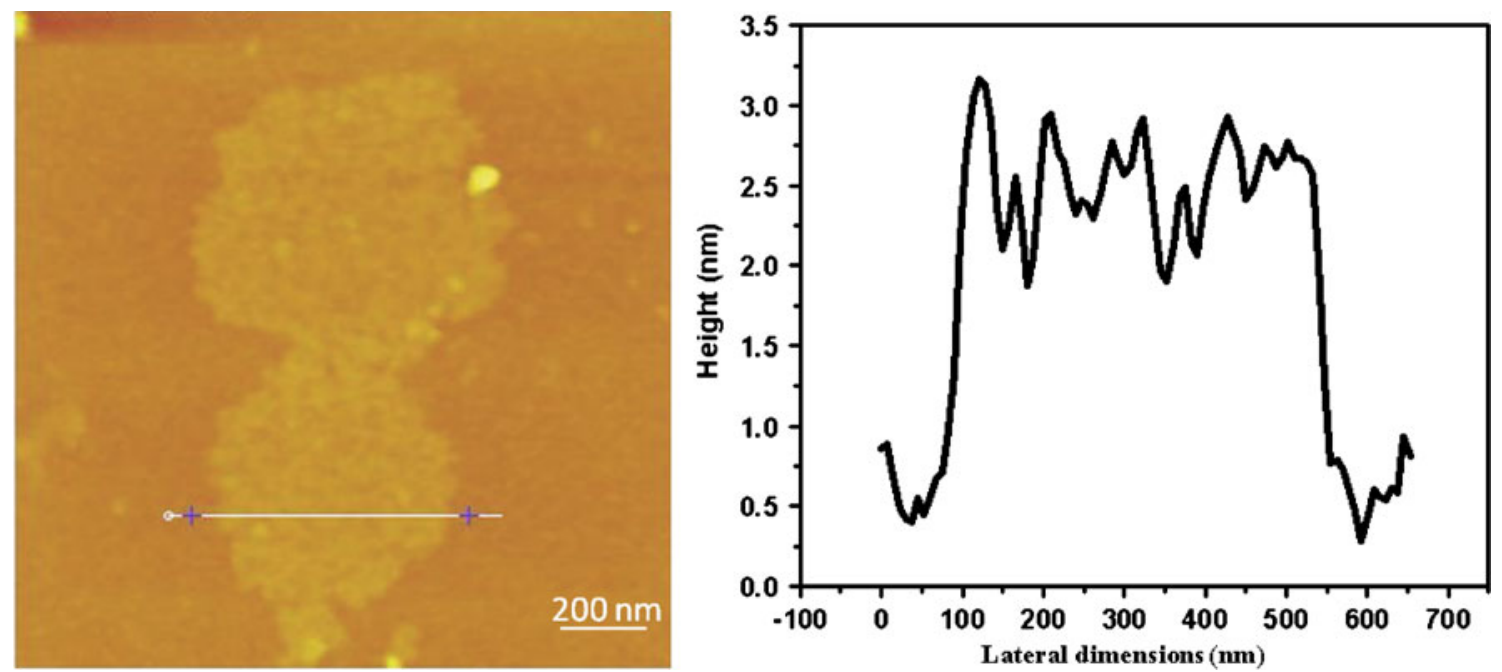

Figure 7. AFM image of $\mathrm{SiO}_{2}$ nanosheets obtained after calcination of $\mathrm{SiO}_{2}$-bonded graphene at $600{ }^{\circ} \mathrm{C}$. Height profile is shown.
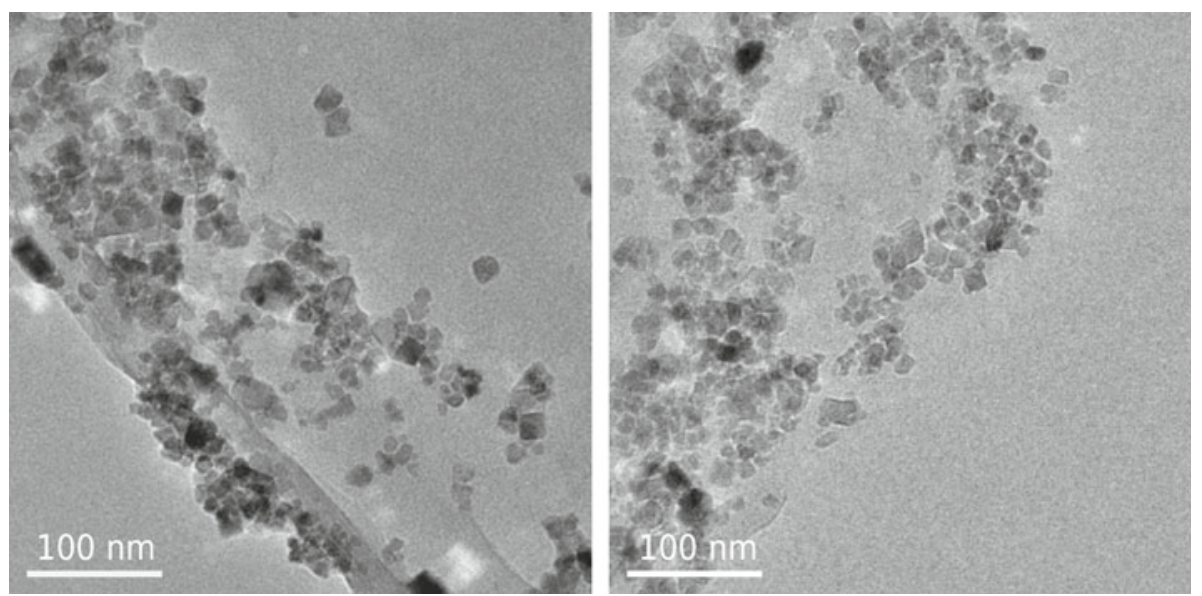

Figure 8. TEM images of $\mathrm{GO}-\mathrm{Fe}_{3} \mathrm{O}_{4}$ composite. 


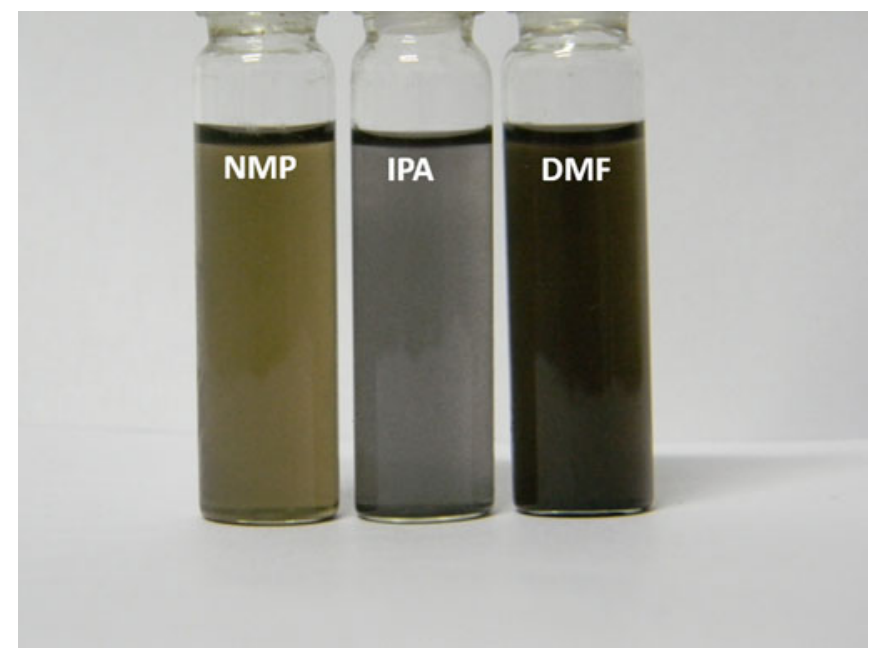

Figure 9. Dispersions of $\mathrm{GO}-\mathrm{Fe}_{3} \mathrm{O}_{4}$ composite in different solvents.

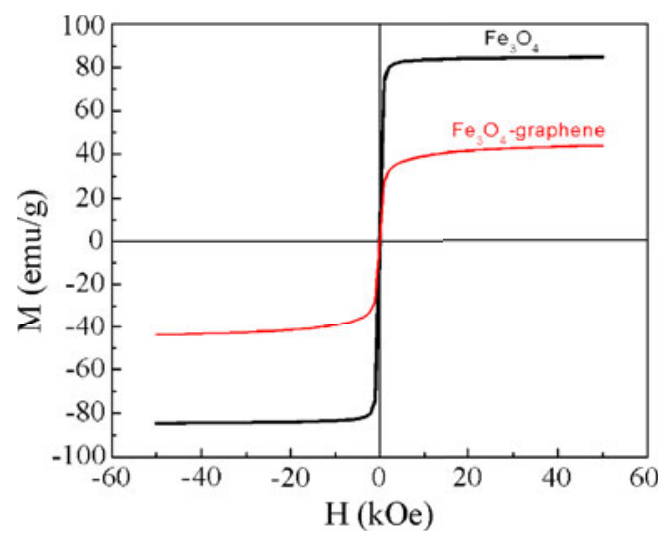

Figure 10. $M-H$ curve of amine-functionalized $\mathrm{Fe}_{3} \mathrm{O}_{4}$ and $\mathrm{GO}-$ $\mathrm{Fe}_{3} \mathrm{O}_{4}$ composite.

on heating up to $350{ }^{\circ} \mathrm{C}$. SEM image (figure $2 \mathrm{~b}$ ) of $\mathrm{G}-\mathrm{TiO}_{2}$ heated at $350{ }^{\circ} \mathrm{C}\left(\mathrm{G}-\mathrm{TiO}_{2}-350\right)$ for $12 \mathrm{~h}$, gives an EDX pattern (see inset of figure $2 \mathrm{~b}$ ) showing the presence of only $\mathrm{Ti}$ and $\mathrm{O}$ and does not show any chlorine. In figures 3(a) and (b), we show TEM images of $\mathrm{G}-\mathrm{TiO}_{2}$ obtained at room temperature and at $350{ }^{\circ} \mathrm{C}$, respectively. On calcining the $\mathrm{TiO}_{2}$-bonded graphene composite at $600{ }^{\circ} \mathrm{C}$ for $12 \mathrm{~h}(\mathrm{G}-$ $\mathrm{TiO}_{2}-600$ ), the graphene sheets get oxidized, yielding $\mathrm{TiO}_{2}$ nanosheets as shown by SEM and TEM images in figures 2(c) and 3(c), respectively. EDX pattern (inset of figure 2c) of the calcined sample confirms the presence of Ti and O. XRD patterns reveal the formation of $\mathrm{TiO}_{2}$ in the anatase phase ( $a=3.785 \AA$ and $c=9.514 \AA$ ) after calcination at $600{ }^{\circ} \mathrm{C}$ for $12 \mathrm{~h}$.

AFM image of $\mathrm{G}-\mathrm{TiO}_{2}-350$ shown in figure 4(a) obtained by the calcination of the composite at $350{ }^{\circ} \mathrm{C}$ corresponds to that of graphene sheets $(\sim 0.8 \mathrm{~nm})$ covered with $\mathrm{TiO}_{2}$. AFM image of $\mathrm{G}-\mathrm{TiO}_{2}-600$ shows thickness of the oxide film to be $\sim 1-2 \mathrm{~nm}$. $\mathrm{TiO}_{2}$ is a well known dielectric material $(\mathrm{Hu}$ et al 2010) with the bulk sample having dielectric constant of 20-30. $\mathrm{TiO}_{2}$ nanosheets obtained by us has a much higher dielectric constant as shown in figure 5 .

Encouraged by the success of preparing $\mathrm{TiO}_{2}$-bonded graphene, we prepared graphene bonded to $\mathrm{SiO}_{2}$ films by using $\mathrm{SiCl}_{4}$ as the reagent. In figure 6(a), we show a SEM image of $\mathrm{SiO}_{2}$-bonded to graphene prepared after 10 cycles of coating and calcined at $350{ }^{\circ} \mathrm{C}$. EDX pattern shows presence of only silicon and oxygen (see inset of figure 6a). A TEM image of $\mathrm{SiO}_{2}$ nanosheets obtained after calcination of $\mathrm{SiO}_{2}$-bonded graphene sheets at $600{ }^{\circ} \mathrm{C}$ is shown in figure 6(b). EDX pattern in figure 6(b) shows presence of only silicon and oxygen (see inset of figure 6b). AFM image of $\mathrm{SiO}_{2}$-bonded graphene heated up to $350{ }^{\circ} \mathrm{C}$ gives $\sim 5-$ $6 \mathrm{~nm}$ thick film. $\mathrm{SiO}_{2}$ nanosheets were amorphous and $\mathrm{SiO}_{2}$ sheets obtained by calcination at $600{ }^{\circ} \mathrm{C}$ were $\sim 2 \mathrm{~nm}$ thick (figure 7). We have also been able to bond $\mathrm{Al}_{2} \mathrm{O}_{3}$ to graphene by using $\mathrm{AlCl}_{3}$ as the reactant. The oxide film was amorphous after calcination at $600{ }^{\circ} \mathrm{C}$.

We have prepared chemically bonded magnetic $\mathrm{Fe}_{3} \mathrm{O}_{4}$ nanoparticles to graphene by functionalizing $\mathrm{Fe}_{3} \mathrm{O}_{4}$ by amine, then reacting it with graphene functionalized with acid chloride groups, resulting in the formation of an amide bond between the two. IR spectrum clearly shows the presence of amide carbonyl stretching band in the graphene$\mathrm{Fe}_{3} \mathrm{O}_{4}$ composite. The morphology of $\mathrm{GO}-\mathrm{Fe}_{3} \mathrm{O}_{4}$ composite particles is shown by TEM images in figure 8. Dense $\mathrm{Fe}_{3} \mathrm{O}_{4}$ particles are found at the edge of the sheets since graphene oxide has most carboxyl functional groups at the edges. The particle size of $\mathrm{Fe}_{3} \mathrm{O}_{4}$ is in the range of $10-15 \mathrm{~nm}$. The GO$\mathrm{Fe}_{3} \mathrm{O}_{4}$ composite can be dispersed in various solvents as can be seen from the photographs in figure 9. In figure 10, we show $M-H$ curves of the $\mathrm{GO}-\mathrm{Fe}_{3} \mathrm{O}_{4}$ composite. The saturation magnetization $\left(M_{\mathrm{s}}\right)$ of $\mathrm{GO}-\mathrm{Fe}_{3} \mathrm{O}_{4}$ is $43.18 \mathrm{emu} / \mathrm{g}$ which is smaller than the $M_{\mathrm{s}}$ value of amine functionalized $\mathrm{Fe}_{3} \mathrm{O}_{4}$ $(84.28 \mathrm{emu} / \mathrm{g})(\mathrm{Li}$ et al 2011).

\section{Conclusions}

Nano films of metal oxides such as $\mathrm{TiO}_{2}$ and $\mathrm{SiO}_{2}$ have been chemically bonded to the graphene surface to yield novel composites. Such composites may have potential applications worthy of exploration. $\mathrm{Fe}_{3} \mathrm{O}_{4}$ particles chemically bonded to graphene exhibit satisfactory magnetization values for use in diagnostics and other applications.

\section{Acknowledgement}

We thank Prof. C N R Rao for suggesting the problem and guidance.

\section{References}

Cao H, Li B, Zhang J, Lian F, Kong X and Qu M 2012 J. Mater. Chem. 229759

Coleman J N et al 2011 Science 331568 
Geim A K and Novoselov K S 2007 Nat. Mater. 6183

Gomathi A, Vivekchand S R C, Govindaraj A and Rao C N R 2005 Adv. Mater. 172757

Hu W, Li L, Tong W and Li G 2010 Chem. Commun. 463113

Hummers W S and Offeman R E 1958 J. Am. Chem. Soc. 80 1339

Kamegawa T, Suzuki N and Yamashita H 2011 Energy Environ. Sci. 41411

Li B, Cao H, Shao J, Qu M and Warner J H 2011 J. Mater. Chem. 215069

Matte H S S R, Gomathi A, Manna A K, Late D J, Datta R, Pati S K and Rao C N R 2010 Angew. Chem. Int. Ed. 494059

Miyauchi M, Nakajima A, Watanabe T and Hashimoto K 2002 Chem. Mater. 142812
Novoselov K S, Geim A K, Morozov S V, Jiang D, Zhang Y, Dubonos S V and Grigorieva I V 2004 Science 306666

Novoselov K S, Jiang D, Schedin F, Booth T J, Khotkevich V V, Morozov S V and Geim A K 2005 Proc. Natl. Acad. Sci. USA 10210451

Rao C N R and Sood A K 2013 (eds) Graphene (Weinheim: Wiley$\mathrm{VCH})$

Rao C N R, Sood A K, Subrahmanyam K S and Govindaraj A 2009 Angew. Chem. Int. Ed. 487752

Wang X, Tabakman S M and Dai H 2008 J. Am. Chem. Soc. 130 8152

Zhang H, Lv X, Li Y, Wang Y and Li J 2010 ACS Nano. 4380

Zhang F, Jin J, Zhong X, Li S, Niu J, Li R and Ma J 2011 Green Chem. 131238 